\title{
Mechanisms of tumor necrosis factor- $\alpha$-induced interleukin-6 synthesis in glioma cells
}

Kumiko Tanabe ${ }^{1 *}$, Rie Matsushima-Nishiwaki ${ }^{2}$, Shinobu Yamaguchi ${ }^{1}$, Hiroki lida', Shuji Dohi ${ }^{1}$, Osamu Kozawa ${ }^{2}$

\begin{abstract}
Background: Interleukin (IL)-6 plays a pivotal role in a variety of CNS functions such as the induction and modulation of reactive astrogliosis, pathological inflammatory responses and neuroprotection. Tumor necrosis factor (TNF)- $\alpha$ induces IL-6 release from rat C6 glioma cells through the inhibitory kappa B $(\mid \kappa B)$-nuclear factor kappa B (NF $\kappa$ B) pathway, p38 mitogen-activated protein (MAP) kinase and stress-activated protein kinase (SAPK)/ c-Jun N-terminal kinase (JNK). The present study investigated the mechanism of TNF- $\alpha$-induced IL- 6 release in more detail than has previously been reported.

Methods: Cultured C6 cells were stimulated by TNF- $\alpha$. IL-6 release from the cells was measured by an enzymelinked immunosorbent assay, and the phosphorylation of $\mid \kappa B, N F \kappa B$, the MAP kinase superfamily, and signal transducer and activator of transcription (STAT) 3 was analyzed by Western blotting. Levels of IL-6 mRNA in cells were evaluated by real-time reverse transcription-polymerase chain reaction.

Results: TNF- $\alpha$ significantly induced phosphorylation of NF $\kappa$ B at Ser 536 and Ser 468, but not at Ser 529 or Ser 276. Wedelolactone, an inhibitor of $\mid \kappa B$ kinase, suppressed both TNF- $\alpha$-induced $I \kappa B$ phosphorylation and NF $\kappa B$ phosphorylation at Ser 536 and Ser 468. TNF- $\alpha$-stimulated increases in IL-6 levels were suppressed by wedelolactone. TNF- $\alpha$ induced phosphorylation of STAT3. The Janus family of tyrosine kinase (JAK) inhibitor I, an inhibitor of JAK 1, 2 and 3, attenuated TNF- $\alpha$-induced phosphorylation of STAT3 and significantly reduced TNF- $\alpha$ stimulated IL-6 release. Apocynin, an inhibitor of NADPH oxidase that suppresses intracellular reactive oxygen species, significantly suppressed TNF- $\alpha$-induced IL- 6 release and mRNA expression. However, apocynin failed to affect the phosphorylation of $1 \kappa \mathrm{B}, \mathrm{NF} \kappa \mathrm{B}, \mathrm{p} 38$ MAP kinase, SAPK/JNK or STAT3.

Conclusion: These results strongly suggest that TNF- $\alpha$ induces IL-6 synthesis through the JAK/STAT3 pathway in addition to P38 MAP kinase and SAPKJNKK in C6 glioma cells, and that phosphorylation of NF $\kappa$ B at Ser 536 and Ser 468 , and NADPH oxidase are involved in TNF- $\alpha$-stimulated IL-6 synthesis.
\end{abstract}

\section{Background}

Tumor necrosis factor (TNF)- $\alpha$ is a potent pro-inflammatory cytokine with a major role in initiating a cascade of activation of other cytokines and growth factors in inflammatory responses [1]. TNF- $\alpha$ is synthesized by microglia, astrocytes and some populations of neurons and has several important functions in the CNS, including injury-mediated microglial and astrocyte activation, regulation of blood-brain barrier permeability, febrile responses, glutamatergic transmission, and synaptic plasticity [2]. TNF- $\alpha$ leads to activation of inhibitory kappa $\mathrm{B}(\mathrm{I} \kappa \mathrm{B})$ by the $\mathrm{I} \kappa \mathrm{B}$ kinase (IKK) complex, which in turn

\footnotetext{
* Correspondence: kumiko-t@m2.gyao.ne.jp

'Department of Anesthesiology and Pain Medicine, Gifu University Graduate School of Medicine, Gifu 501-1194, Japan
}

leads to $\mathrm{I} \kappa \mathrm{B}$ polyubiquitination and subsequent degradation by proteasome [3]. Consequently, nuclear factor kappa $\mathrm{B}(\mathrm{NF} \kappa \mathrm{B})$ is phosphorylated, liberated from $\mathrm{I} \kappa \mathrm{B}$ and translocates to the nucleus, where it binds to the promoter regions of $\mathrm{NF} \kappa \mathrm{B}$ responsive genes and initiates transcription of genes such as those for the proinflammatory cytokines interleukin (IL)-6, IL-1, and TNF- $\alpha$ [1,3]. Each member of NF $\kappa \mathrm{B}$ family, such as p65, c-REL, RELB, p105/p50 and p100/p52, can form homodimers, as well as heterodimers with one another. The main activated form of $\mathrm{NF} \kappa \mathrm{B}$ is a heterodimer of the p65 subunit [1,3]. Different phosphorylation patterns may recruit different transcriptional cofactors to the subunit and induce distinct profiles of gene expression [3]. TNF$\alpha$ induces IL- 6 release through the phosphorylation of 
$\mathrm{NF} \kappa \mathrm{B}, \mathrm{p} 38$ mitogen-activated protein (MAP) kinase and stress-activated protein kinase (SAPK)/c-Jun N-terminal kinase (JNK) in rat C6 glioma cells [4]. TNF- $\alpha$ induces IL-6 expression through the p65 phosphorylation at Ser 276, but not at Ser 529 or Ser 536 in murine fibroblasts [5]. However, the details of $\mathrm{NF} \kappa \mathrm{B}$ phosphorylation in glial cells have not been clarified.

In addition to the $\mathrm{I} \kappa \mathrm{B}-\mathrm{NF} \kappa \mathrm{B}$ pathway, the main intracellular signaling pathway activated by cytokines is the Janus family of tyrosine kinase (JAK)-signal transducer and activator of transcription (STAT) pathway. The activation of the JAK-STAT pathway leads to a rapid signaling from the cell surface to the nucleus [6]. JAK proteins are phosphorylated when cytokines bind to specific receptors, and subsequently activate STATs. The activated STATs translocate to the nucleus and transmit the signals, where they then bind to specific consensus sequences, thereby triggering gene transcription [6]. Seven STAT proteins have been identified in mammalian cells [6]. Among them, STAT1 and STAT3 play important roles in post-ischemic brain damage $[7,8]$. IL$1 \beta$, an important cytokine, phosphorylates STAT3 in C6 cells [9]. However, the precise role of the JAK-STAT pathway in glial cells remains to be elucidated.

Oxidative stress refers to a state with elevated levels of intracellular reactive oxygen species (ROS; such as superoxide radicals and hydrogen peroxide) production and impaired function of antioxidant defense mechanisms. NADPH oxidase is a multi-subunit enzyme that catalyzes the reduction of molecular oxygen and the oxidation of NADPH to generate superoxide radicals [10]. $\mathrm{NADPH}$ oxidase is widely distributed and has a variety of functions, such as regulation of immune system, cell growth, cell death and endothelial functions. While NADPH oxidase-derived ROS are necessary for normal cellular functions, excessive oxidative stress can contribute to pathological conditions. ROS play critical roles in TNF- $\alpha$ signaling [11]. NF $\kappa \mathrm{B}$ acts as a suppressor of intracellular ROS formation in TNF- $\alpha$ treated cells [11]. Crosstalk occurs between JNK and NF $\kappa \mathrm{B}$, and a role for ROS in TNF- $\alpha$ signaling has emerged. The intermediacy of ROS in the crosstalk between JNK and NF $\kappa \mathrm{B}$ is; 1 ) a TNF- $\alpha$-induced increase in intracellular ROS is responsible for sustained JNK activation, as well as impaired $\mathrm{NF} \kappa \mathrm{B}$ activation; 2) NF $\kappa \mathrm{B}$ regulates the expression of several key antioxidant enzymes or proteins to eliminate ROS, thus serving as a negative feedback loop; and 3) activated JNK is capable of promoting ROS production, thus forming a positive feedback loop between JNK and ROS [11]. NADPH oxidase in the CNS is associated with memory, neurodegenerative diseases, cerebral ischemic injury and central regulation of the cardiovascular system [10]. NADPH oxidase is found mainly in neurons [12]. Amyloid $\beta$ induces NADPH oxidase activation and causes oxidative stress in astrocytes [13]. However, the role of NADPH oxidase in astrocytes remains to be fully clarified.

The present study investigated the phosphorylation of specific residues of NF $\kappa \mathrm{B}$ is association with TNF- $\alpha$-stimulated IL-6 synthesis in C6 glioma cells. Furthermore, the involvement of the JAK-STAT pathway and NADPH oxidase in the TNF- $\alpha$-stimulated IL- 6 synthesis was examined.

\section{Methods \\ Materials}

TNF- $\alpha$ was obtained from Peprotech (London, UK). IL6 enzyme-linked immunosolvent assay (ELISA) kit was purchase from R\&D System (Minneapolis, MN). Wedelolactone, JAK inhibitor I and apocynin were obtained from Calbiochem-Novabiochem Co. (La Jolla, CA). Phospho-specific $\mathrm{I} \kappa \mathrm{B}, \mathrm{I} \kappa \mathrm{B}$, phospho-specific NF $\kappa \mathrm{B}$ (Ser 536, Ser 468 and Ser 276), NF $\kappa$ B, phospho-specific p38 MAP kinase, p38 MAP kinase, phospho-specific SAPK/ JNK, SAPK/JNK, phospho-specific STAT3, STAT3 and glyceraldehyde-3-phosphate dehydrogenase (GAPDH) antibodies were purchased from Cell Signaling Technology (Beverly, MA). Phospho-specific NF $\kappa \mathrm{B}$ (Ser 529) antibody was purchased from abcam (Cambridge, MA). An enhanced chemiluminescence Western blotting detection system was obtained from GE Healthcare UK. Ltd. (Buckinghamshire, England). Other materials and chemicals were obtained from commercial sources. Wedelolactone and JAK inhibitor I were dissolved in dimethyl sulfoxide. Apocynin was dissolved in ethanol. The maximum concentration of dimethyl sulfoxide or ethanol was $0.1 \%$, which did not affect either the assay for IL-6, the Western blot analysis or the mRNA expression.

\section{Cell culture}

Rat C6 glioma cells, obtained from the American Type Culture Collection (Rockville, MD), were seeded into $35-\mathrm{mm}\left(5 \times 10^{4}\right.$ cells/dish $)$ or $90-\mathrm{mm}\left(2 \times 10^{5}\right.$ cells/ dish) diameter dishes and maintained in Dulbecco's modified Eagle's medium (DMEM) containing 10\% fetal bovine serum at $37^{\circ} \mathrm{C}$ in a humidified atmosphere of $5 \%$ $\mathrm{CO}_{2} / 95 \%$ air. The medium was exchanged for serumfree DMEM after 6 days. The cells were then used for experiments after $24 \mathrm{~h}$. The cells were pretreated with wedelolactone, JAK inhibitor I or apocynin for $60 \mathrm{~min}$ before TNF- $\alpha$ stimulation when indicated.

\section{Assay for IL-6}

Cultured cells (35-mm diameter dishes) were stimulated with $10 \mathrm{ng} / \mathrm{ml} \mathrm{TNF-} \alpha$ in serum-free DMEM for $36 \mathrm{~h}$. The conditioned medium was collected at the end of the incubation, and IL-6 concentration was measured 
using an ELISA kit. The absorbance of each sample at $450 \mathrm{~nm}$ and $540 \mathrm{~nm}$ was measured with a Multiscan JX ELISA reader (Thermo Labsystems, Helsinki, Finland). Absorbance was corrected with reference to a standard curve.

\section{Western blot analysis}

Cultured cells (90-mm diameter dishes) were stimulated with $10 \mathrm{ng} / \mathrm{ml}$ TNF- $\alpha$ in serum-free DMEM for the indicated periods. The cells were washed twice with phosphate-buffered saline and then lysed and sonicated in a lysis buffer containing $62.5 \mathrm{mM}$ Tris/ $\mathrm{HCl}(\mathrm{pH} 6.8)$, $2 \%$ sodium dodecyl sulfate (SDS), $50 \mathrm{mM}$ dithiothreitol, and $10 \%$ glycerol. The sample was used for the Western blotting analysis as described previously [9]. The samples were separated by SDS-polyacrylamide gel electrophoresis by the method of Laemmli [14] in 10\% polyacrylamide gels. Western blot analysis was performed using phospho-specific $\mathrm{I} \kappa \mathrm{B}$ antibodies, $\mathrm{I} \kappa \mathrm{B}$ antibodies, phospho-specific NF $\kappa \mathrm{B}$ antibodies, NF $\kappa \mathrm{B}$ antibodies, phospho-specific p38 MAP kinase antibodies, p38 MAP kinase antibodies, phospho-specific SAPK/ JNK antibodies, SAPK/JNK antibodies, phospho-specific STAT3 antibodies, STAT3 antibodies or GAPDH antibodies, with peroxidase-labeled antibodies raised in goat against rabbit IgG being used as second antibodies. Peroxidase activity on polyvinylidene difluoride membrane was visualized on X-ray film by utilizing an enhanced chemiluminescence Western blotting detection system.

\section{Real-time reverse transcription (RT)-polymerase chain reaction (PCR)}

Cultured cells (35-mm diameter dishes) were stimulated with $10 \mathrm{ng} / \mathrm{ml} \mathrm{TNF}-\alpha$ for the indicated periods. Total RNA was isolated and transcribed into complementary DNA (cDNA) using Trizol reagent and Omniscript Reverse Transcriptase Kit. Real-time PCR was performed using a Light Cycler system (Roche Diagnostics, Basel, Switzerland) in the capillaries and Fast-Start DNA Master SYBR Green I provided with the kit. Sense and antisense primers for mouse IL-6 or GAPDH mRNA were purchased from Takara Bio Inc. (Tokyo, Japan) (primer set ID:MA039013). The amplified products were determined by a melting curve analysis and agarose electrophoresis. IL-6 mRNA levels were normalized with those of GAPDH mRNA.

\section{Statistical analysis}

The data were analyzed by ANOVA followed by Bonferroni's method for multiple comparisons between pairs. $P<0.05$ was considered to be significant. All data are presented as the mean \pm SD of triplicate determinations. Each experiment was repeated three times with similar results.

\section{Results}

Effect of TNF- $\alpha$ on $\mathrm{I} \kappa \mathrm{B}$ and $\mathrm{NF} \kappa \mathrm{B}$ phosphorylation in C6 cells

The $\mathrm{I} \kappa \mathrm{B}-\mathrm{NF} \kappa \mathrm{B}$ pathway is involved in TNF- $\alpha$-induced IL-6 release from C6 glioma cells [4]. NF $\kappa \mathrm{B}$ binds to its consensus sequence on a target gene promoting transcription and upregulation of gene expression [3]. The phosphorylation of $\mathrm{NF} \kappa \mathrm{B}$ at different sites shows different gene expressions [3]. The effects of TNF- $\alpha$ on the phosphorylation of four serine residues (Ser 536, Ser 529 and Ser 468, Ser 276) were examined. TNF- $\alpha$ significantly induced phosphorylation of $\mathrm{NF} \kappa \mathrm{B}$ at Ser 536 and Ser 468 in a time-dependent manner. Ser 536 phosphorylation was observed at $5 \mathrm{~min}$ and decreased after 20 min, and Ser 468 phosphorylation was enhanced at 5 min and maintained a plateau for up to $30 \mathrm{~min}$ (Fig. 1). On the contrary, Ser 529 and Ser 276 were phosphorylated in unstimulated cells, but they were not affected by TNF- $\alpha$ stimulation.

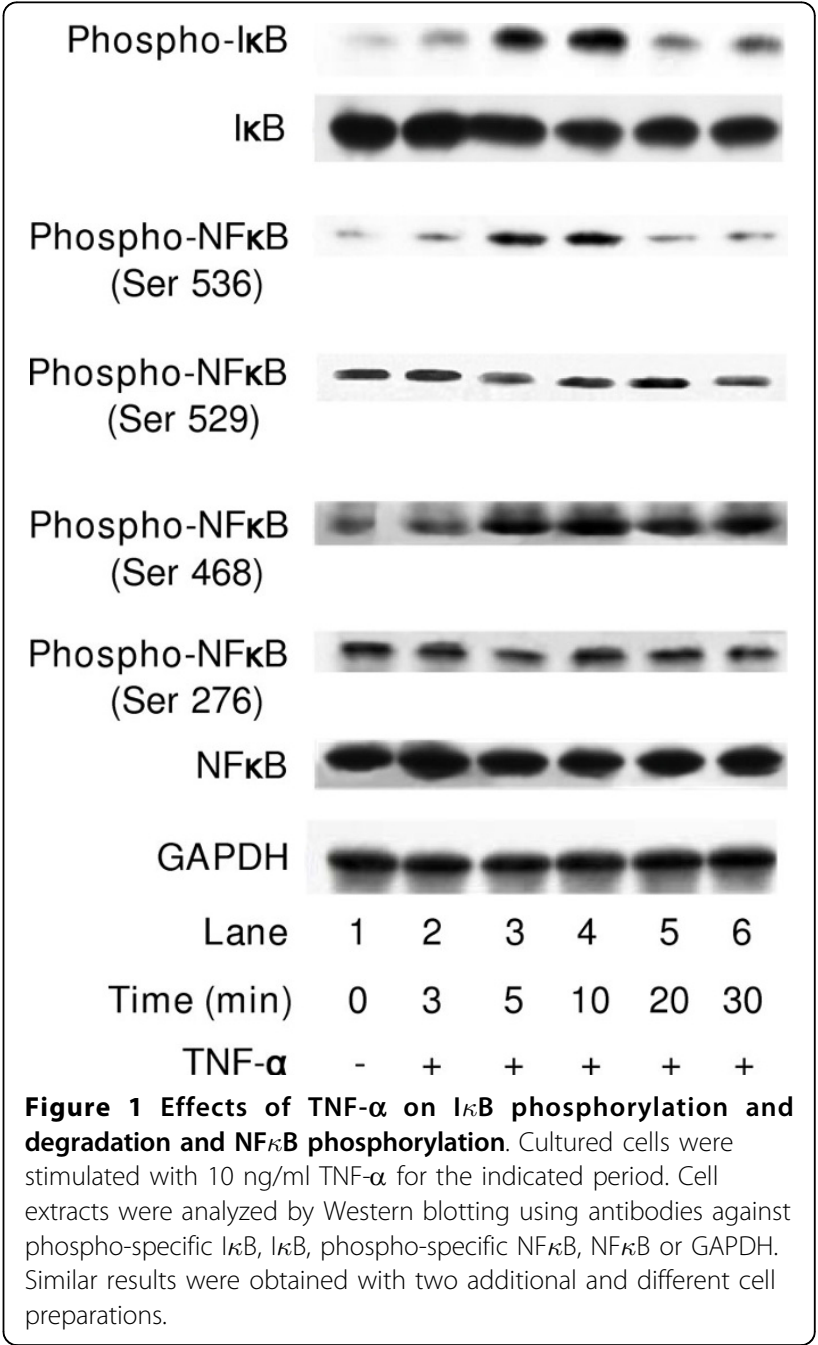




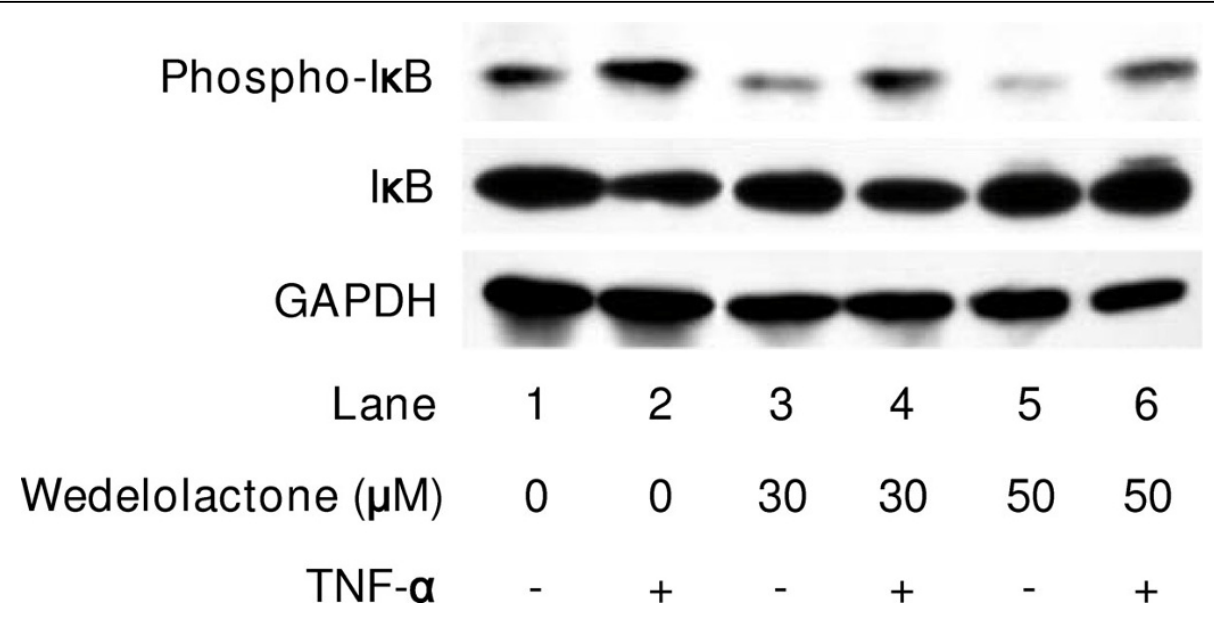

Figure 2 Effects of wedelolactone on TNF- $\alpha$-induced phosphorylation and degradation of $\mathbf{I} \kappa \mathbf{B}$. Cultured cells were pretreated with various concentrations of wedelolactone or vehicle for $60 \mathrm{~min}$, and then stimulated with $10 \mathrm{ng} / \mathrm{ml}$ TNF- $\alpha$ or vehicle for 10 min. Cell extracts were analyzed by Western blotting using antibodies against phospho-specific $\mid \kappa B$, $\mid \kappa B$ or GAPDH. Similar results were obtained with two additional and different cell preparations.

\section{Effect of wedelolactone on TNF- $\alpha$-induced NF $\kappa$ B}

\section{phosphorylation in $\mathrm{C} 6$ cells}

Wedelolactone $(30 \mu \mathrm{M})$, an inhibitor of IKK [15], suppressed TNF- $\alpha$-induced I $\kappa$ B phosphorylation (Fig. 2). In addition, phosphorylation of $\mathrm{NF} \kappa \mathrm{B}$ at both Ser 536 and Ser 468 was inhibited by wedelolactone (Fig. 3). Wedelolactone, which by itself had little effect on the IL-6 levels, significantly suppressed TNF- $\alpha$-induced IL6 release. The suppressive effect was concentrationdependent in the range between 1 and $50 \mu \mathrm{M}$ (Fig. 4).

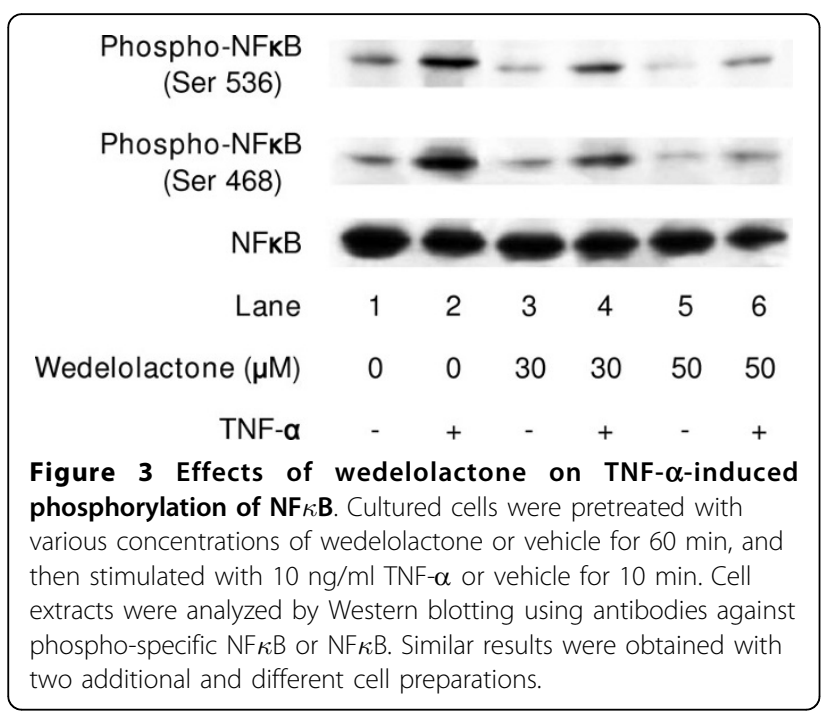

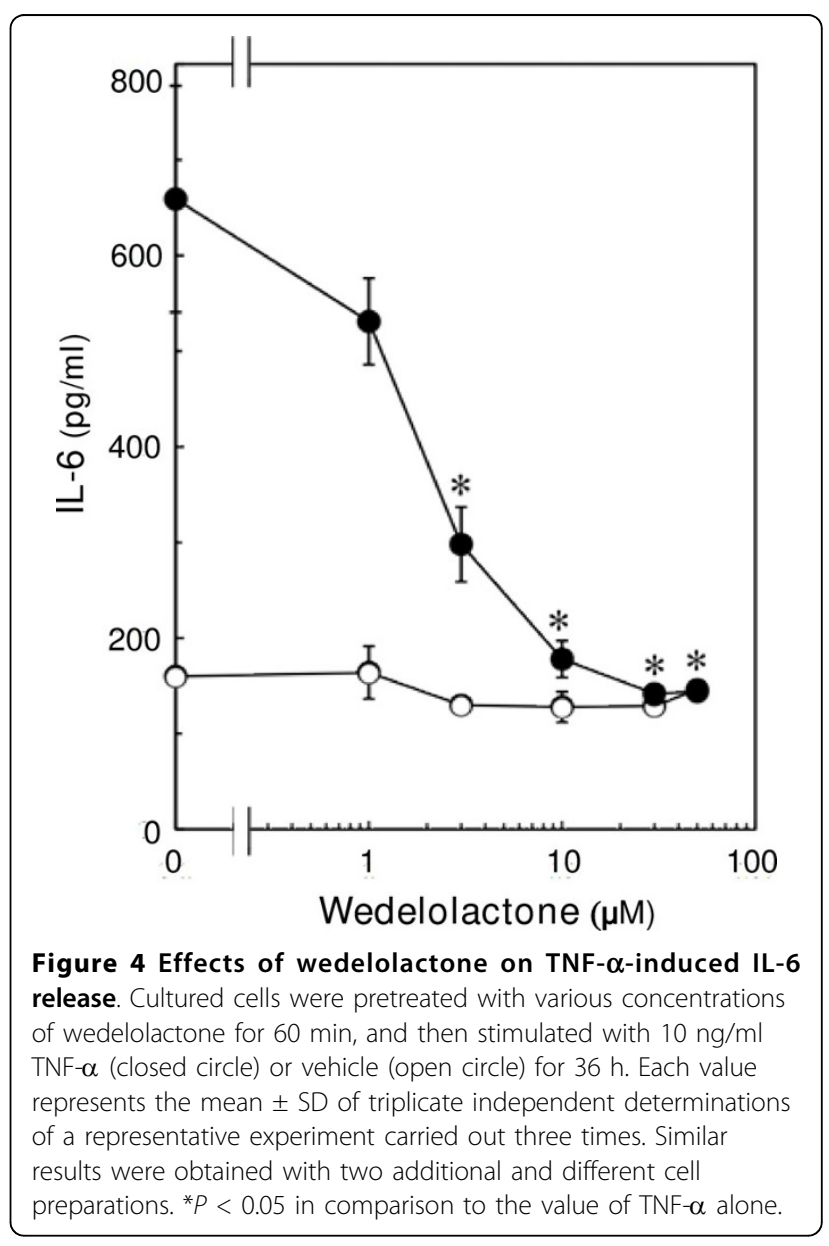




\section{Effect of JAK inhibitor I on TNF- $\alpha$-induced IL- 6 release from $\mathrm{C} 6$ cells}

The JAK-STAT pathway has an essential role in driving a variety of biological responses to cytokines [6]. The effect of TNF- $\alpha$ on the phosphorylation of STAT3 was examined. Phosphorylation of STAT3 was marked at $60 \mathrm{~min}$, and reached a peak $150 \mathrm{~min}$ after stimulation (Fig. 5). The effect of JAK inhibitor I, an inhibitor of JAK 1, 2 and 3 [16], on TNF- $\alpha$-induced IL- 6 release was examined. JAK inhibitor I (10 $\mathrm{nM})$, which by itself had little effect on the IL- 6 levels, significantly suppressed TNF- $\alpha$-induced IL-6 release (Fig. 6A). In addition, JAK inhibitor I truly suppressed TNF- $\alpha$-induced phosphorylation of STAT3 in a concentration-dependent manner

\section{Phospho-STAT3 \\ STAT3 \\ Lane \\ Time (min) $\quad 0 \quad 30 \quad 60 \quad 90 \quad 120 \quad 150 \quad 180$ \\ TNF- $\alpha-+++++$}

Figure 5 Effects of TNF- $\alpha$ on STAT3 phosphorylation. Cultured cells were stimulated with $10 \mathrm{ng} / \mathrm{ml}$ TNF- $\alpha$ for the indicated period. Cell extracts were analyzed by Western blotting using antibodies against phospho-specific STAT3 or STAT3. Similar results were obtained with two additional and different cell preparations.

\section{A}

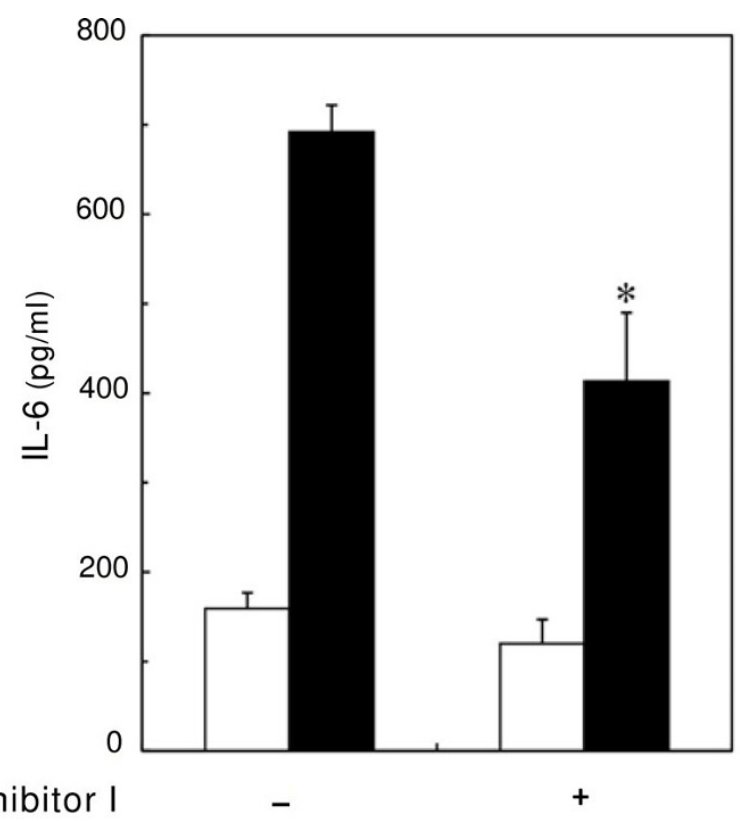

JAK inhibitor I

TNF- $\alpha$

B

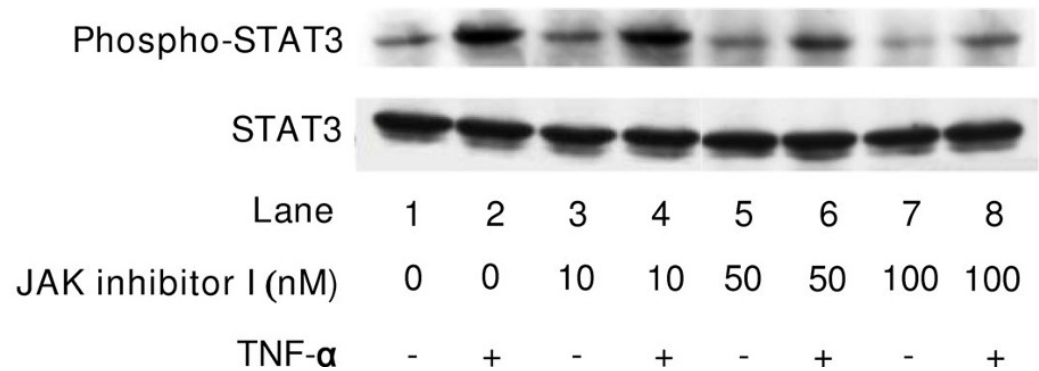

Figure 6 Effect of JAK inhibitor I on TNF- $\alpha$-induced IL- 6 release. (A) Cultured cells were pretreated with 10 nM JAK inhibitor I for 60 min, and then stimulated with $10 \mathrm{ng} / \mathrm{ml}$ TNF- $\alpha$ or vehicle for $36 \mathrm{~h}$. Each value represents the mean \pm SD of triplicate independent determinations of a representative experiment carried out three times. ${ }^{*} P<0.05$ in comparison to the value of TNF- $\alpha$ alone. (B) Cultured cells were pretreated with various concentrations JAK inhibitor I or vehicle for $60 \mathrm{~min}$, and then stimulated with $10 \mathrm{ng} / \mathrm{ml}$ TNF- $\alpha$ or vehicle for 150 min. Cell extracts were analyzed by Western blotting using antibodies against phospho-specific STAT3 or STAT3. Similar results were obtained with two additional and different cell preparations. 
between 10 and $100 \mathrm{nM}$ (Fig. 6B). The TNF- $\alpha$-induced phosphorylation of STAT3 was observed later than phosphorylation of $\mathrm{I} \kappa \mathrm{B}, \mathrm{NF} \kappa \mathrm{B}$ or MAP kinases. This delayed phosphorylation is consistent with a previous report, showing that IL-1 $\beta$ phosphorylates STAT3 60 min after stimulation in C6 cells [9].

\section{Effect of apocynin on TNF- $\alpha$-induced IL- 6 release from $\mathrm{C} 6$ cells}

Apocynin, an inhibitor of NADPH oxidase [17], which by itself had little effect on IL-6 levels, significantly suppressed TNF- $\alpha$-induced IL- 6 release (Fig. 7). This suppressive effect was concentration-dependent in the range between 1 and $100 \mu \mathrm{M}$. In addition, TNF- $\alpha$ (10 ng/ml) significantly induced IL-6 mRNA expression at $6 \mathrm{~h}$ after stimulation (Fig. 8), thus suggesting that TNF- $\alpha$ stimulates the synthesis of IL- 6 in C6 glioma cells. The suppressive effect of apocynin on IL- 6 release by TNF- $\alpha$ could be due to protein synthesis suppression. Apocynin (100 $\mu \mathrm{M})$ suppressed TNF- $\alpha$-induced IL-6 mRNA

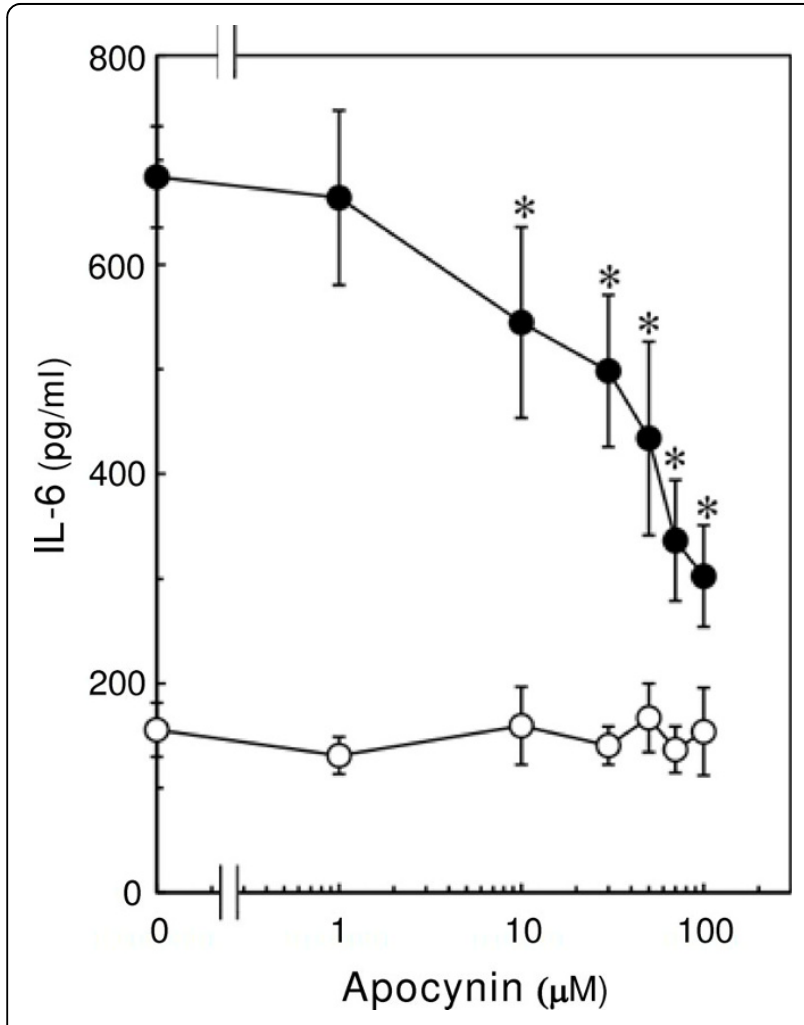

Figure 7 Effect of apocynin on TNF- $\alpha$-induced IL- 6 release. Cultured cells were pretreated with various concentrations apocynin for $60 \mathrm{~min}$, and then stimulated with $10 \mathrm{ng} / \mathrm{ml} \mathrm{TNF- \alpha}$ (closed circle) or vehicle (open circle) for $36 \mathrm{~h}$. Each value represents the mean \pm SD of triplicate independent determinations of a representative experiment carried out three times. Similar results were obtained with two additional and different cell preparations. ${ }^{*} P<0.05$ in comparison to the value of TNF- $\alpha$ alone.

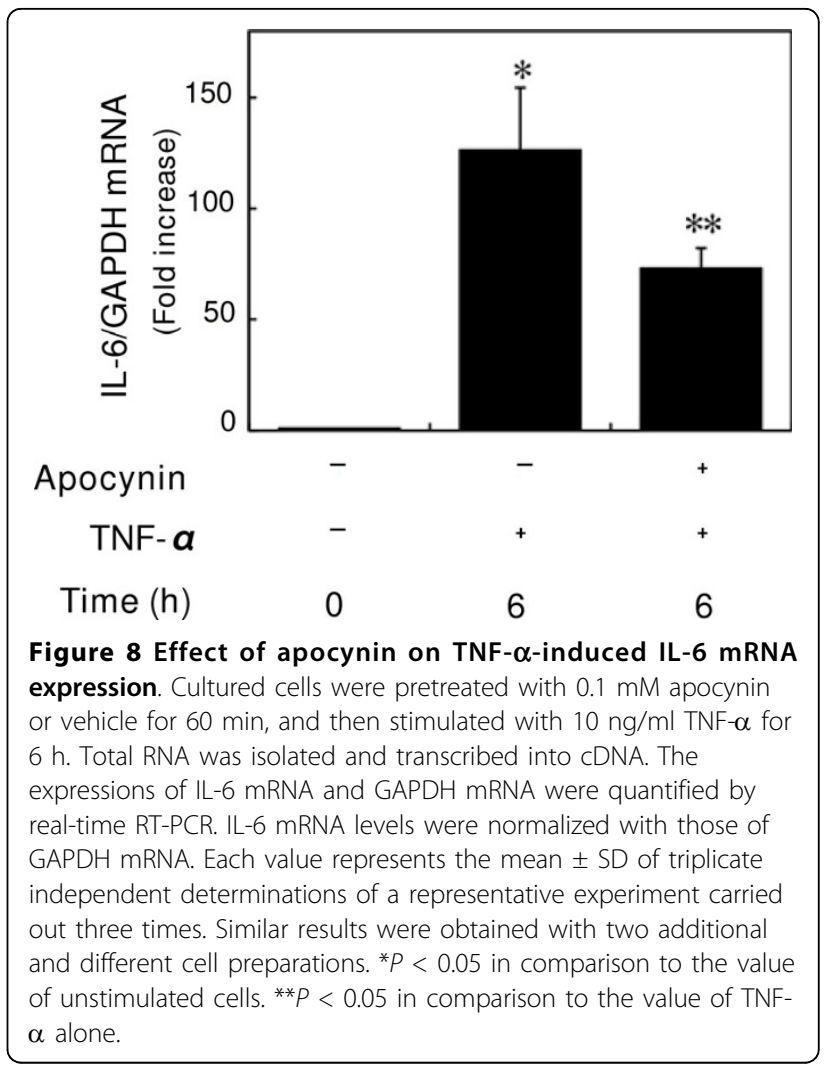

expression (Fig. 8). The effects of apocynin on TNF- $\alpha-$ induced phosphorylation of $\mathrm{I} \kappa \mathrm{B}, \mathrm{NF} \kappa \mathrm{B}$, p38 MAP kinase, SAPK/JNK or STAT3 were examined to determine whether the apocynin-effect on TNF- $\alpha$-induced-IL- 6 release is dependent upon activation of the $\mathrm{I} \kappa \mathrm{B}-\mathrm{NF} \kappa \mathrm{B}$ pathway, the MAP kinase superfamily, and the JAKSTAT3 pathway in C6 cells. However, apocynin failed to affect the phosphorylation of these kinases (Fig. 9).

\section{Discussion}

TNF- $\alpha$-induced IL- 6 release is dependent on the I $\kappa \mathrm{B}$ $\mathrm{NF} \kappa \mathrm{B}$ pathway [4]. Several sites in the $\mathrm{N}$-terminal Rel homology domain, including Ser 276 , or in the C terminus transactivation domain region play a pivotal role in the finer regulation of $\mathrm{NF} \kappa \mathrm{B}$ transcriptional activity [3]. Different phosphorylation patterns may induce distinct profiles of gene expression [3]. Therefore, the present study investigated which residue is involved in the TNF$\alpha$-stimulated IL- 6 synthesis in C6 glioma cells. TNF- $\alpha$ significantly induced the phosphorylation of NF $\kappa \mathrm{B}$ at Ser 536 and Ser 468, but not at Ser 529 and Ser 276. Ser 276 phosphorylation by TNF- $\alpha$ is essential for IL- 6 production in murine fibroblasts [5]. However, Ser 276 is phosphorylated in unstimulated rat $\mathrm{C} 6$ glioma cells and the levels do not change with TNF- $\alpha$ stimulation. Furthermore, wedelolactone, an IKK inhibitor [15], truly reduced the TNF- $\alpha$-induced IL- 6 release and NF $\kappa \mathrm{B}$ 


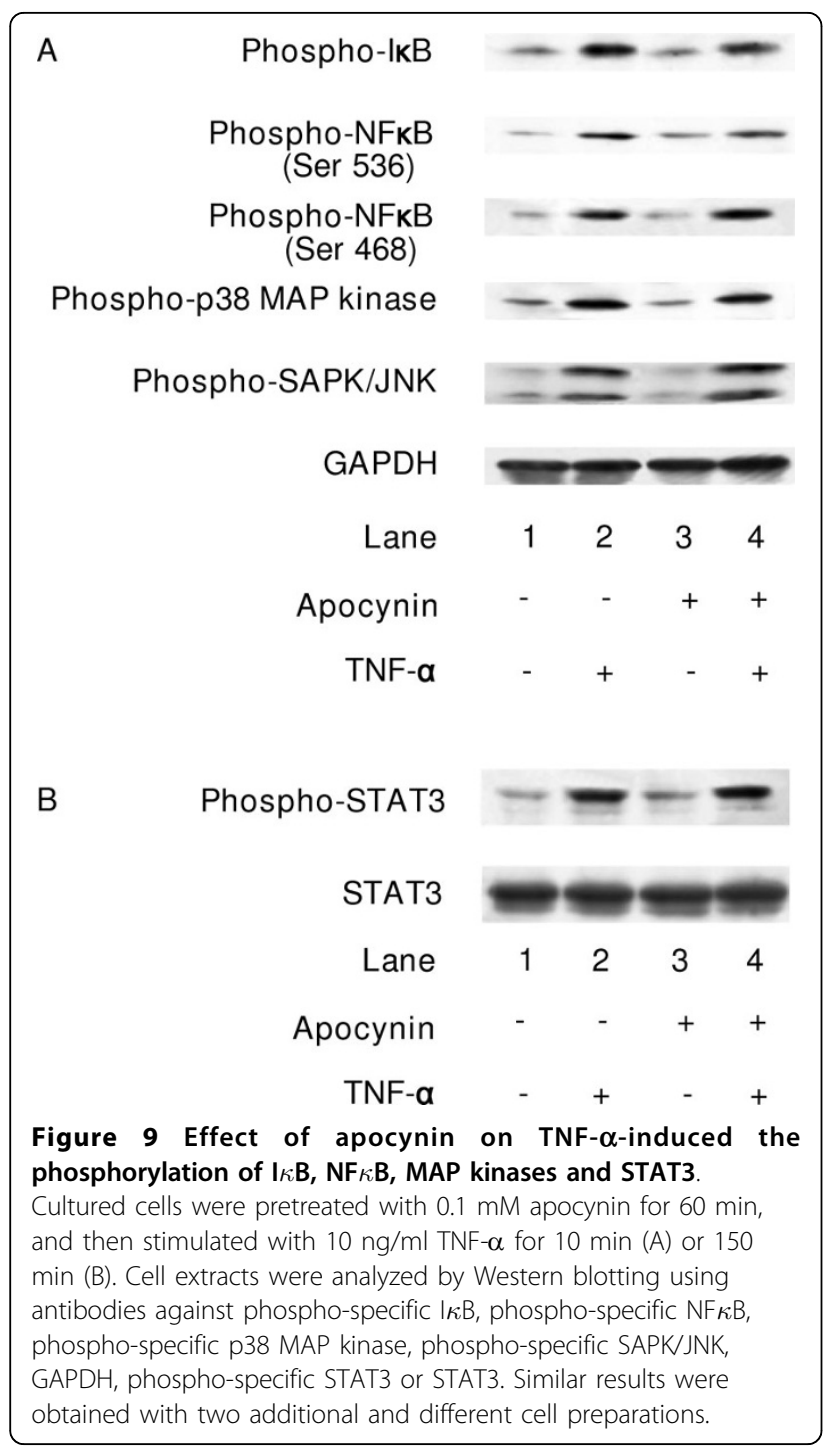

phosphorylation at Ser 536 and Ser 468. Therefore, these findings suggest that TNF- $\alpha$ induces IL- 6 release through phosphorylation of NF $\kappa$ B at Ser 536 and Ser 468 in C6 glioma cells.

JAKs are constitutively associated with many cytokine receptors [6]. The binding of cytokines to a receptor associated with JAKs leads to the tyrosine phosphorylation of the receptor, and generates a docking site for STATs [6]. The STATs are thus phosphorylated and translocate to the nucleus where they may activate transcription of several genes [6]. The present study demonstrated that TNF- $\alpha$ significantly induced phosphorylation of STAT3 in C6 cells, and that JAK inhibitor I, an inhibitor of JAK 1, 2 and 3 [16], suppressed TNF- $\alpha$-induced IL- 6 release. In addition, JAK inhibitor I suppressed TNF- $\alpha$-induced STAT3 phosphorylation. Therefore, these results suggest that TNF- $\alpha$ induces IL-
6 release through the JAK-STAT3 pathway in addition to p38 MAP kinase and SAPK/JNK in C6 glioma cells.

Finally, apocynin, an inhibitor of NADPH oxidase [17], significantly suppressed TNF- $\alpha$-induced IL- 6 release and mRNA expression. The action point of NADPH oxidase in TNF- $\alpha$-stimulated IL-6 synthesis in C6 glioma cells was investigated. However, apocynin did not affect TNF- $\alpha$-induced $\mathrm{I} \kappa \mathrm{B}, \mathrm{NF} \kappa \mathrm{B}, \mathrm{p} 38$ MAP kinase, SAPK/ JNK or STAT3 phosphorylation. It therefore seems unlikely that NADPH oxidase functions at a point of these kinases in TNF- $\alpha$-induced IL- 6 synthesis in C6 glioma cells. The current findings are consistent with a previous report, in which ROS was said to be regulated by $\mathrm{NF} \kappa \mathrm{B}$ and JNK activation [11].

IL-6 plays a key role in B cell maturation and drives acute inflammatory responses $[18,19]$. IL- 6 is produced in neurons, microglia and astrocytes, and it plays a pivotal role in a variety of CNS functions such as induction and modulation of reactive astrogliosis, pathological inflammatory responses and neuroprotection $[18,20]$. Various stimuli, such as infection, traumatic brain injury, ischemia and CNS diseases produce key inflammatory mediators including IL-6 [18]. TNF- $\alpha$ induces other cytokines and it also plays important roles in ROS production [11]. In addition, NADPH oxidase plays an important role in the immune system in the brain [10]. However, the exact role of NADPH oxidase in astrocytes, not in neurons, remains to be fully clarified. The present study suggests that NADPH oxidase regulates the immune system in the CNS via regulation of IL-6 synthesis in astrocytes.

In conclusion, the current results strongly suggest that TNF- $\alpha$ induces IL- 6 synthesis through phosphorylation of NF $\kappa \mathrm{B}$ at Ser 536 and Ser 468, and JAK-mediated phosphorylation of STAT3 in addition to p38 MAP kinase and SAPK/JNK in C6 glioma cells, and that oxidative stress is associated with IL-6 synthesis.

\section{Acknowledgements}

Sources of support: This work was supported in part by a Grant-in-Aid for Scientific Research (Nos. 19209050 and 20591798) from the Ministry of Education, Science, Sports, and Culture, Japan. We are very grateful to Yoko Kawamura for her skillful technical assistance.

\section{Author details}

'Department of Anesthesiology and Pain Medicine, Gifu University Graduate School of Medicine, Gifu 501-1194, Japan. '2Department of Pharmacology, Gifu University Graduate School of Medicine, Gifu 501-1194, Japan.

\section{Authors' contributions}

$\mathrm{KT}$ and OK conceived the study, participated in its design and coordination analyzed the data and drafted the manuscript. KT, RM-N and SY performed the experiments. $\mathrm{HI}$ and SD provided useful advice. All authors read and approved the final manuscript.

\section{Competing interests}

The authors declare that they have no competing interests. 


\section{References}

1. Li Q, Verma IM: NF $\kappa$ B regulation in the immune system. Nat Rev Immunol 2002, 2:725-734.

2. McCoy MK, Tansey MG: TNF signaling inhibition in the CNS: implications for normal brain function and neurodegenerative disease. I Neuroinflammation 2008, 5:45.

3. Hayden MS, Ghosh S: Signaling to NF- $\kappa$ B. Genes Dev 2004, 18:2195-2224.

4. Yamaguchi S, Tanabe K, Takai S, Matsushima-Nishiwaki R, Adachi S, lida H, Kozawa O, Dohi S: Involvement of Rho-kinase in tumor necrosis factor- $\alpha$ induced interleukin-6 release from C6 glioma cells. Nerochem Int 2009, 55:438-445.

5. Okazaki T, Sakon S, Sasazuki T, Sakurai H, Doi T, Yagita H, Okumura K, Nakano H: Phosphorylation of serine 276 is essential for p65 NF- $\kappa \mathrm{B}$ subunit-dependent cellular responses. Biochem Biophys Res Commun 2003, 300:807-812.

6. Dell'Albani P, Santangelo R, Torrisi L, Nicoletti VG, Stella AMG: Role of the JAK/STAT signal transduction pathway in the regulation of gene expression in CNS. Neurochem Res 2003, 28:53-64.

7. Planas AM, Gorina R, Chamorro A: Signalling pathways mediating inflammatory responses in brain ischaemia. Biochem Soc Trans 2006, 34:1267-1270.

8. Yi J-H, Park SW, Kapadia R, Vemuganti R: Role of transcription factors in mediating post-ischemic cerebral inflammation and brain damage. Neurochem Int 2007, 50:1014-1027.

9. Tanabe K, Nishimura K, Dohi S, Kozawa O: Mechanisms of interleukin-1 $\beta$ induced GDNF release from rat glioma cells. Brain Res 2009, 1274:11-20.

10. Infanger DW, Sharma RV, Davisson RL: NADPH oxidases of the brain: distribution, regulation, and function. Antioxid Redox Signal 2006, 8:1583-1596.

11. Shen H-M, Pervaiz S: TNF receptor superfamily-induced cell death: redoxdependent execution. FASEB J 2006, 20:1589-1598.

12. Serrano F, Kolluri NS, Wientjes FB, Card JP, Klann E: NADPH oxidase immunoreactivity in the mouse brain. Brain Res 2003, 988:193-198.

13. Abramov AY, Jacobson J, Wientjes F, Hothersall J, Canevari L, Duchen MR: Expression and modulation of an NADPH oxidase in mammalian astrocytes. J Neurosci 2005, 25:9176-9184.

14. Laemmli UK: Cleavage of structural proteins during the assembly of the head of bacteriophage T4. Nature 1970, 227:680-685.

15. Kobori M, Yang Z, Gong D, Heissmeyer V, Zhu H, Jung YK, Gakidis MAM Rao A, Sekine T, Ikegami F, Yuan C, Yuan J: Wedelolactone suppresses LPS-induced caspase-11 expression by directly inhibiting the IKK complex. Cell Death Differ 2004, 11:123-130.

16. Thompson JE, Cubbon RM, Cummings RT, Wicker LS, Frankshun R, Cunningham BR, Cameron PM, Meinke PT, Liverton N, Weng Y, DeMartino JA: Photochemical preparation of a pyridone containing tetracycle: a Jak protein kinase inhibitor. Bioorg Med Chem Lett 2002, 12:1219-1223.

17. Hart BA, Simons JM: Metabolic activation of phenols by stimulated neutrophils: a concept for a selective type of anti-inflammatory drug. Biotechnol Ther 1992, 3:119-135.

18. Van Wagoner NJ, Benveniste EN: Interleukin-6 expression and regulation in astrocytes. J Neuroimmunol 1999, 100:124-139.

19. Naugler WE, Karin M: The wolf in sheep's clothing: the role of interleukin6 in immunity, inflammation and cancer. Trends Mol Med 2008, 14:109-119.

20. Farina C, Aloisi F, Meinl E: Astrocytes are active players in cerebral innate immunity. Trends Immunol 2007, 28:138-145.

\section{Submit your next manuscript to BioMed Central and take full advantage of:}

- Convenient online submission

- Thorough peer review

- No space constraints or color figure charges

- Immediate publication on acceptance

- Inclusion in PubMed, CAS, Scopus and Google Scholar

- Research which is freely available for redistribution 